\title{
Handling tempting food in a non-consummatory context reduces subsequent consumption of other tempting food: an extension beyond sweet snacks.
}

\author{
Hannelore Goddyn ${ }^{a}$, Siegfried Dewitte ${ }^{a^{*}}$ \\ Accepted for Publication in Food Quality and Preference
}

\begin{abstract}
The modern environment is characterized by an abundance of tempting food. One potential procedure to help consumers deal with food temptations is the pre-exposure procedure. It has been demonstrated that pre-exposing people to a tempting sweet product in a situation that subtly discourages consumption reduces their subsequent consumption of similar sweet temptations. This study investigated whether the pre-exposure effect could be observed with savory products as well, and whether the effect crossed from sweet to savory food and the other way around. The study exposed 144 participants to either salty sticks, chocolate sticks, or wooden sticks (control condition) in the context of geometric puzzles. Compliance with the task implied no consumption. Participants' subsequent consumption of salty nuts or chocolate coated nuts was then measured in the context of a taste test that followed the initial puzzle task. The results revealed that pre-exposing participants to tasty sticks that they handled but did not consume, reduced their subsequent snack consumption compared to the control condition, irrespective of taste. This suggests that the pre-exposure effect generalizes to savory food products, and the consumption reduction effect crosses tastes. These findings are valuable for both researchers and practitioners interested in understanding and developing paradigms to reduce the consumption of high-caloric food.
\end{abstract}

Keywords: Pre-exposure; tempting food; sweet; savory; taste; food consumption

a Behavioral Engineering Research Group, Faculty of Business and Economics, KU Leuven, Naamsestraat 69, 3000 Leuven, Belgium

${ }^{*}$ Corresponding author: siegfried.dewitte@kuleuven.be 


\section{Introduction}

With over 250 food decisions every day (Wansink \& Sobal, 2007), people are facing a continuous struggle between controlling food intake and immediate indulgence. Especially the abundance of high-caloric food has been seen as one of the major factors contributing to the increasing prevalence of obesity (e.g. Blundell et al., 2005). Exposure to food temptations is known to boost consumption (e.g. Lambert, Neal, Noyes, Parker, \& Worrel, 1991). Therefore, strategies to deal with everyday temptations are mainly focusing on either banning temptations (for example, removing soft drinks from vending machines in schools) or on the effortful resistance to temptations (for example by committing to pay an amount of money when failing to reach a previously specified goal; Appelhans, French, Pagoto, \& Sherwood, 2016). Banning temptations can only be implemented in restricted environments (e.g. schools, home environment) and it does not seem to have positive spill-over effects to situations outside the restricted environment (e.g. Loth, MacLehose, Larson, Berge, \& NeumarkSztainer, 2016). Resistance strategies often rely on executive functions, as for example inhibitory control (Jansen, Houben, \& Roefs, 2015). However, it has been shown that in tempting situations, executive functioning is often weakened (Appelhans et al., 2016). Therefore the focus of this paper will be on the further extension of a procedure that may solve both challenges simultaneously: the pre-exposure procedure. In the pre-exposure procedure, individuals are exposed to a tempting food item in a context where eating would interfere with task compliance (e.g. making a word puzzle with candy letters). Recent research on the pre-exposure procedure suggests that exposure to temptations while resisting the temptation may boost rather than decrease successful resistance to temptation in certain well-designed circumstances (de Boer, de Ridder, de Vet, Grubliauskiene, \& Dewitte, 2015; Duh, Grubliauskiene, \& Dewitte, 2016; Geyskens, Dewitte, Pandelaere, \& Warlop, 2008). These studies demonstrate that exposure to tempting food in a task context that requires consumers to use the temptation in a way that prevents them from eating it, results in reduced consumption of a similar snack in a subsequent consumption opportunity. Up to now, this effect has only been investigated with sweet snacks in both the pre-exposure phase and the consumption phase. Considering that people are not only tempted by sweet snacks, this paper 
tests whether the pre-exposure effect also holds for savory snacks, and whether the effect crosses over tastes.

\subsection{The pre-exposure procedure}

Exposure to food temptations puts people in an indulgence-resistance conflict. This conflict can be solved by either giving in to the temptation (and eat the food), or by resisting and not eating the snack. Although most research is focused on how temptations lead to indulgence (e.g. Baumeister, 2002; Papies, Stroebe, \& Aarts, 2008), some researchers also focus on how temptations can actually boost self-control. Under specific conditions, self-control can be boosted rather than reduced in the context of a temptation (Kroese, Evers, \& De Ridder, 2009; Myrseth, Fishbach, \& Trope, 2009; Trope \& Fishbach, 2000). While previously it was thought that this effect required the presence of a food restriction goal that the temptation activated (Fishbach, Friedman, \& Kruglanski, 2003; Kroese et al., 2009), more recent evidence demonstrated that the presence of the food restriction goal is not required (e.g. de Boer et al., 2015; Geyskens, et al., 2008; Grubliauskiene \& Dewitte, 2014). In the original pre-exposure task used by Geyskens et al. (2008), participants were instructed to link taste descriptions of Quality Street $\odot$ candy to the wrappings of the candies (which were physically present). This task implicitly invites them to refrain from consuming in the first phase. In the second phase, and presented as a different study, the participants engaged in a so-called taste test. They were asked to rate M\&M's $\subset$ and were allowed to consume as much as they wanted. The main finding was that participants who had been exposed to candy (without eating) in the first phase, ate less during the taste test than those that had not been exposed to tempting candy before. In other words this study and its replications suggested that the experimental task can provide a temporary food restriction goal that conflicts with eating. There is some evidence that the behavioral conflict in the first phase (i.e. eating the food versus task compliance) triggers cognitive control processes to solve this conflict (de Boer et al., 2015; Dewitte, Bruyneel, \& Geyskens, 2009), a mechanism based on cognitive control theory (Miller \& Cohen, 2001). These cognitive control processes might divert the attention from the taste as a way to solve the behavioral conflict. The strategy to divert attention from the taste would then spill over to subsequent situations with a similar behavioral conflict (Dewitte et al., 2009).

Interestingly, follow-up studies have replicated the pre-exposure effect with different manipulations (word puzzles with food, drawings with food, self-inflicted exposure in a waiting task), different populations (children, South-African sample) and a time-lag between 
the two phases (de Boer et al., 2015; Duh et al., 2016; Grubliauskiene \& Dewitte, 2014). In this paper, we want to extend the applicability of this procedure over taste. The next section will focus on the importance of taste for the applicability of the pre-exposure procedure.

\subsection{A taste specific or general effect?}

Previous research on the pre-exposure effect per se has only focused on sweet temptations (in both phases). It is not clear from these studies, however, whether the procedure would work for other tastes (e.g. savory temptations in both phases). Given that humans have an unlearned preference for sweet food (Benton, 2004; Birch, 2003) and learn a preference for salty food very early in life (Schwartz, Issanchou, \& Nicklaus, 2009; Stein, Cowart, \& Beauchamp, 2012), savory temptations should produce an equally robust pre-exposure effect, as long as the products used are experienced as tempting, and induce a behavioral conflict. For example, Fedoroff, Polivy and Herman (2003) demonstrated the enhanced response of restrained eaters to food cues both for sweet (cookies) as savory (pizza) food. A second, and equally important question is whether the procedure would work for dissimilar tastes as well (sweet temptations in the first phase and savory in the second phase, or the other way around). Given the variety of food cues in the daily environment, a generalizable pre-exposure procedure could be a very promising tool in the battle against overconsumption. According to the cognitive control theory, Dewitte et al. (2009) demonstrated that the behavioral conflict induced by the preexposure phase should be similar to the conflict in the subsequent phase in order to generate the pre-exposure effect. However, based on that study it is not clear how similar this conflict should be. Based on food exposure studies, both a food-specific effect or a more generalizable effect could be possible. For example, several studies demonstrated food cue specificity after exposure to the smell of a tempting food (Chambaron et al., 2015; Fedoroff et al., 2003; Gaillet-Torrent et al., 2014; Lambert et al., 1991; Ramaekers et al., 2016). In addition, according to habituation theory, repeated exposure to a stimulus reduces responding to this stimulus. However, switching from one taste to another would recover the response to the food (Epstein, Temple, Roemmich, \& Bouton, 2009), although habituation is slower to emerge when there is no consumption (McSweeney and Murphy, 2009). However, studies focusing on the self-regulatory processes do not imply specificity. Kleiman, Hassin, and Trope (2014) showed that cognitive control processes induce a generalized control mind set. In the food domain, Kroese, Evers, and de Ridder (2009 \& 2011) showed that exposure to tempting food reduced subsequent snack intake (of another type). 
Therefore, the aim of this study is two-fold. First, we will test whether the pre-exposure effect can be produced with savory tempting snacks (in both phases). Second, we will manipulate the similarity of the tastes in phase 1 and 2 and test whether the pre-exposure extends across tastes. In order to explore the scope of the procedure, we start from the core paradigm to test the pre-exposure procedure (Duh et al. 2016; Geyskens et al., 2008). In this core version of the paradigm, participants are exposed to sweet temptations (vs. control stimuli that look similar) while they are engaged in a task that prevents them from eating the temptations. In the second phase, participants engage in a taste-test of a (different) sweet snack and their actual consumption is measured. In the present extension, we add a salty condition (in addition to control and sweet) to the first phase, and in the taste test, we add a savory version of the taste test (in addition to the sweet version of it). If the pre-exposure effect can be produced with savory tempting snacks (in both phases), but does not generalize over taste (crossing), we expect a main effect of taste (salty and sweet < control) and an interaction effect between pre-exposure manipulation in phase 1 and taste in phase 2 (sweet exposure reduces sweet consumption and savory exposure reduces savory consumption but no cross link). If the pre-exposure effect extends across taste, we also expect a main effect of preexposure, without an interaction (control versus sweet pre-exposure and control versus salty pre-exposure, irrespective of taste in the taste test).

\section{Method}

\subsection{Design and participants}

The study used a 3 (pre-exposure: sweet, salty, or control) by 2 (taste test: sweet or salty) between-subjects design. Participants were randomly assigned to one of the conditions, with the restriction that the pre-exposure conditions were run in separate sessions of 6-10 participants for procedural efficiency.

A total of 144 participants participated in the study in return for a participation fee (6 EUR). They were part of an international subject pool of students of a large Western European university and were recruited via an online registration system. Participants were aged between 18 and $61(M=23.9 ; S D=5.9)$, and $44 \%$ was female. The study took place in a behavioral lab with semi-enclosed cubicles positioned in such a way that participant did not see each other during the study. All studies took place between 11am and 18am. The studies were run in English. The study was approved by the internal ethical board with number G2015-08-300. 


\subsection{Temptation manipulation (phase 1 of the pre-exposure procedure)}

On entering the laboratory, participants were assigned to a computer. All instructions were given via the online survey tool Qualtrics (Qualtrics, Provo, UT). After answering a question on how hungry they were (on a 7-point scale), all participants were instructed to solve eight matchstick puzzles. The puzzle was shown on the computer screen, but participants were supposed to solve the puzzles on the desk with the sticks that were handed to them at the start of the session. In the pre-exposure (PE) conditions, the puzzles had to be made with either chocolate sticks (of the brand LU Mikado; SWEET PE; for an example see Figure 1) or salty pretzel sticks (of the brand Everyday; SALTY PE) which implied that they had to manipulate the tempting food without being expected to eat them since they all received the exact amount needed to solve the puzzles (15 sticks). In the control conditions (CTR), the same puzzles had to be solved with wooden sticks. They could work on each puzzle for 40 seconds. After $40 \mathrm{~s}$ the program auto-advanced to the next puzzle. Not a single participant consumed any of the sticks in the pre-exposure phase.

Figure 1. Example of a matchstick puzzle to be solved with LU Mikado sticks (SWEET PE). Participants received 15 sticks to solve the puzzles. Each puzzle was presented on the computer screen and had to be solved on the desk with the sticks.
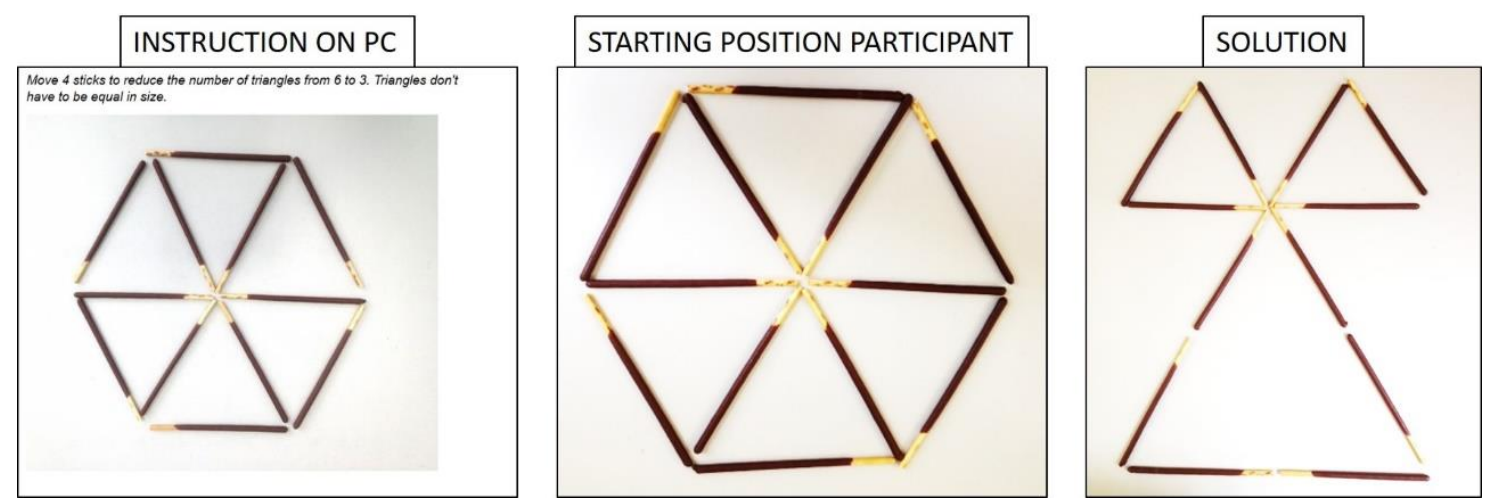

\subsection{Consumption task (phase 2 of the pre-exposure procedure)}

After phase 1, the sticks were removed and all participants received two bowls of the same volume of a tempting snack. In the sweet taste condition one bowl was filled with $600 \mathrm{~g}$ peanut $\mathrm{M} \& \mathrm{Ms}^{\odot}$, while the other bowl was filled with $600 \mathrm{~g}$ chocolate peanuts from a private label (both had an energy density of about $5.1 \mathrm{kcal} / \mathrm{g}$ ). In the savory condition, participants received one bowl of $400 \mathrm{~g}$ Duyvis $\mathrm{Crac} \mathrm{A} \mathrm{Nut}^{\circledR}$, and one bowl of $400 \mathrm{~g}$ private label crunchy 
nuts (both had an energy density of about $5.4 \mathrm{kcal} / \mathrm{g}$ ). Participants were told they participated in a comparative taste test of brand products versus their private label counterpart. Private labels are very similar products that are not branded and were included to make the taste test involving. Note that keeping the volume constant entailed that the bowls in the two taste conditions had a different weight, as the salty peanuts weighted less per volume. Appendix 1 shows pictures of the two bowls in the two taste conditions. Participants were first asked a couple of knowledge and preference questions about the two products. Then they proceeded with the taste test. Participants got questions on both the brand and private label product. The full list of question can be found in Appendix 2.

\subsection{Measures}

\subsubsection{Consumption}

Each of the bowls was weighted before and after the taste test. The difference (summed across the bowls) reflects the amount consumed and serves as the main dependent variable.

Following the tradition in the behavioral literature we used this amount as an indication of restrained eating and hence of self-control (Herman and Polivy, 1975). The reasoning is that people need to eat only a few units to be able to comply with the task but that there is no specified maximum amount. Exerting self-control here would imply that participants sample only a few (enough to assess the product characteristics), whereas those who do not exert selfcontrol would eat more than that. Obviously the amount eaten is determined by many other factors (hunger, liking, impulsiveness, restraint, ...), some of which we measured and controlled for. We check the effect of the manipulations on the amount eating and assume that the differences can be taken as an indication of self-control.

\subsubsection{Trait measures}

After the taste test, we added three trait scales as control variables.

Restraint Scale (Herman \& Polivy, 1980) - Restraint was measured by the Revised Restraint Scale. This scale consists of 10 items related to dieting habits and eating behavior, rated on a 4- or 5-point scale. The total score varies from 0-35, with higher scores indicating more restraint behavior. The Cronbach's alpha for the total scale was 0.75 in this study. UPPS impulsive behavioral scale (Whiteside \& Lynam, 2001) - The UPPS is a self-report measure that consists of 45 items, assessing four aspects of impulsivity, urgency, (lack of) perseverance, (lack of) premeditation and sensation seeking. All items are scored from 1='I 
disagree strongly" to 4= "I agree strongly". The Cronbach's alpha for the four subscales were $0.83,0.68,0.83$ and 0.87 , respectively.

Trait Self-Control scale (Tangney, Baumeister, \& Boone, 2004) - Trait self-control was measured with the 13-item Brief Self-Control. Participants indicated on a 4-point scale (from $1=$ "Not at all" to $4=$ "Very much") how well each statement was applicable to them. The total scale score was calculated as the mean of all 13 items. Cronbach's alpha was 0.85 .

\subsubsection{Liking measures and descriptives}

At the end of the study, participants had to indicate how much they liked the products presented in the study, including those of phase 1, on a visual analogue scale from 0 to 100 . The main purpose was to exclude participants who had a very low liking score for the taste test product (0). Age and gender were asked together with height and weight in order to calculate each participant's BMI $\left(\mathrm{kg} / \mathrm{m}^{2}\right)$. We then probed their idea about the study and found that no-one guessed the purpose of the study. We finally debriefed them about the purpose of the study.

\subsection{Statistical analysis plan}

We cleaned the data before analysis. We omitted seven participants who did not follow the instructions in the study by not engaging in at least one of the parts. We also removed participants who did not like the food of their taste test at all (a score of 0 on a 100 point scale, $\mathrm{n}=3$ ). An outlier analysis revealed four participants whose consumption deviated $3 S D$ or more from their group mean. This left us with 130 participants. Table 1 shows that there were no systematic differences between the conditions on the control variables, suggesting that randomization was successful.

As is often the case in taste test data, the distribution of the amount consumed was skewed (see Appendix 3). To avoid that differences at the right tail would dominate the results, we log-transformed the observations. Furthermore, because we used different products in our two taste test conditions (sweet and salty), differences between taste conditions may be due to product specific elements (e.g. weight density). Indeed, the mean consumption in the sweet taste condition $(M=15.55 \mathrm{~g}, S D=1.31 \mathrm{~g})$ was significantly higher than that in the savory taste group $(M=12.87 \mathrm{~g} ; S D=1.42 \mathrm{~g} ; F(1,128)=8.55 ; p=0.004)$, possibly because of a higher weight density which resulted from the fact that we kept the volume constant across conditions (see method and appendix 1). To avoid distortion from these irrelevant factors, we standardized 
the observations per product category to construct the final dependent variable: amount consumed (unit less)

As a final preparatory step we checked the influence of the potential control variables (traits, hunger, liking, wanting, gender, BMI, and age) on consumption. The actual analysis was an ANCOVA with amount consumed as the dependent variable, pre-exposure condition (3 levels: sweet, salt, and control) and taste test (2 levels: sweet or salty) as independent variables, and the significant control variables as covariates. We report the F-statistics for the main and interactions effect. Specific contrasts tests among the three pre-exposure conditions were conducted with post-hoc analyses (Tukey), which are reported with a p-value.

After this core analysis, we conducted additional analyses to explore interactions with the control variables we measured (gender, traits, etc.). Note that these analyses are underpowered when taken to the highest level of the three-way interaction because they split the cells in two. Null effects can therefore not be reliably interpreted. Positive effects can only be taken as an indication.

Table 1

Summary of descriptive statistics (mean and standard deviations) per experimental condition

\begin{tabular}{lllllll}
\hline Variable & \multicolumn{3}{c}{ sweet taste test } & \multicolumn{3}{c}{ savory taste test } \\
& CTR & SWEET PE & SALTY PE & Control & SWEET PE & SALTY PE \\
& $(\mathrm{n}=22)$ & $(\mathrm{n}=22)$ & $(\mathrm{n}=23)$ & $(\mathrm{n}=23)$ & $(\mathrm{n}=19)$ & $(\mathrm{n}=21)$ \\
\hline AGE & $23.68(3.58)$ & $24.00(8.87)$ & $23.70(5.52)$ & $25.43(7.92)$ & $23.37(3.53)$ & $23.29(4.01)$ \\
BMI & $22.95(2.75)$ & $22.09(3.37)$ & $21.47(3.33)$ & $22.79(3.52)$ & $22.06(2.47)$ & $22.79(3.96)$ \\
TRAIT SC & $3.01(0.73)$ & $3.05(0.58)$ & $3.00(0.59)$ & $2.85(0.67)$ & $2.99(0.73)$ & $2.77(0.74)$ \\
RS & $14.36(5.38)$ & $14.32(6.19)$ & $11.43(4.31)$ & $13.35(5.43)$ & $12.53(5.36)$ & $12.14(7.78)$ \\
URGENCY & $28.80(5.24)$ & $29.18(5.85)$ & $29.13(6.79)$ & $29.48(5.90)$ & $25.63(6.64)$ & $26.80(5.18)$ \\
PREMEDIATION & $31.14(4.76)$ & $31.29(4.33)$ & $32.36(7.52)$ & $31.13(5.09)$ & $34.21(3.29)$ & $34.00(4.53)$ \\
PERSEVERANCE & $28.80(5.24)$ & $29.50(4.52)$ & $30.78(4.21)$ & $29.10(3.27)$ & $30.79(3.38)$ & $30.62(3.87)$ \\
SENSATION & $35.95(6.97)$ & $35.14(7.31)$ & $33.43(8.05)$ & $35.13(8.87)$ & $34.79(5.65)$ & $31.52(7.18)$ \\
SEEKING & & & & & &
\end{tabular}

$\overline{\mathrm{SC}}=$ self-control; $\mathrm{RS}=$ restraint scale; $\mathrm{PE}=$ pre-exposure

3. Results

The preliminary analysis showed that only hunger and the wanting for the product in the taste test were significantly related to consumption $(r=0.29, p=0.001 ; r=0.28, p=0.002$ 
respectively). We included them in the analysis as covariates. The ANCOVA revealed a significant main effect of pre-exposure $(F(2,122)=9.55 ; p<0.001)$. Post-hoc contrast tests showed that participants who made puzzles with chocolate sticks or with pretzel sticks in the pre-exposure phase both ate less snacks in the consumption phase than participants that used wooden sticks to solve the puzzles ( $p<0.001$ and $p=0.041$, respectively). The average amount eaten did not differ between chocolate and pretzel sticks $(p=0.18)$.

Relevant for our research question, no significant pre-exposure*taste interaction was observed $(F(2,122)=0.82$, ns. $)$. Consistent with the pre-analysis, both hunger and wanting were positively related to consumption (Hunger: $F(1,122)=14.69$; $p<0.001$; Wanting: $F(1,122)=4.43 ; p=0.037)^{1}$.

As previously indicated, the significant main effect and the lack of an interaction effect indicate that the pre-exposure effect extends across taste (see Figure 2). Because the SWEET PE-CTR and SALTY PE-CTR contrasts are both significant, irrespective of the taste used in the taste test, we can conclude that the pre-exposure effect works for salty snacks, and crosses taste. Exposure to unhealthy snacks (whether they are sweet or salty) in a situation that subtly discourages consumption reduces subsequent consumption of a tempting snack, whether it is sweet of salty.

\subsection{Exploratory analyses}

An ANCOVA as above including gender and its interactions revealed a main effect of gender $(F(2,116)=23.27 ; p<0.001)$, with men $(M=18.35 \mathrm{~g} ; S E=1.45 \mathrm{~g})$ eating more than women $(M=10.18 \mathrm{~g} ; S E=0.93 \mathrm{~g})$. In addition, the main effect of pre-exposure was again observed $(F(2,116)=12.51 ; p<0.001)$. Post-hoc contrast tests revealed that both the SWEET PE and SALTY PE group consumed less than the CTR group ( $p<0.001$ and $p=0.033$, respectively). Remarkably, the gender*pre-exposure interaction was significant $(F(2,116)=4.90 ; p=0.009$; Figure 3). For women, the simple effects show the same pattern as described before. Post-hoc tests showed that both the women exposed to chocolate sticks (SWEET PE) and to pretzel sticks (SALTY PE) ate less of the tempting snacks, irrespective of taste, in the second phase ( $p<0.001$ and $p=0.014$, respectively). In men, the pre-exposure effect was not significant $(p=0.51)$, although a similar pattern was present in the data. No significant three-way

\footnotetext{
${ }^{1}$ An analysis (two-way ANOVA) without both covariates showed the same main effect of pre-exposure $(F(2,124)=6.25 ; p=0.003)$. Both the main effect of taste $(F(1,124)=0.023)$ in phase 2 as well as the interaction between pre-exposure and flavor $(F(2,124)=1.00)$ did not reach significance. Pairwise comparisons indicated a significant differences between consumption after exposure to chocolate sticks and wooden sticks $(p=0.002)$, while the comparison between salty and wooden sticks was in the same direction but not significant $(p=0.21)$.
} 
interaction (gender*pre-exposure*taste) was observed $(F(2,116)=0.29$, ns). Analogous analyses with the other exploratory variables (e.g. impulsiveness) did not reveal any modulations of the core findings mentioned above.

Figure 2. The pre-exposure effect for sweet and savory snacks. Performing a task with chocolate sticks (SWEET PE; white bars) or pretzel sticks (SALTY PE; grey bars) without eating these sticks induces reduced consumption of another tempting snack in a subsequent consumption phase in comparison with performing this task with wooden sticks (CTR; black bars). This effect occurs irrespective of the taste of the tempting food in this second phase. Bars represent estimated marginal means, displayed as the untransformed data to facilitate the interpretation, error bars represent standard error of the mean.

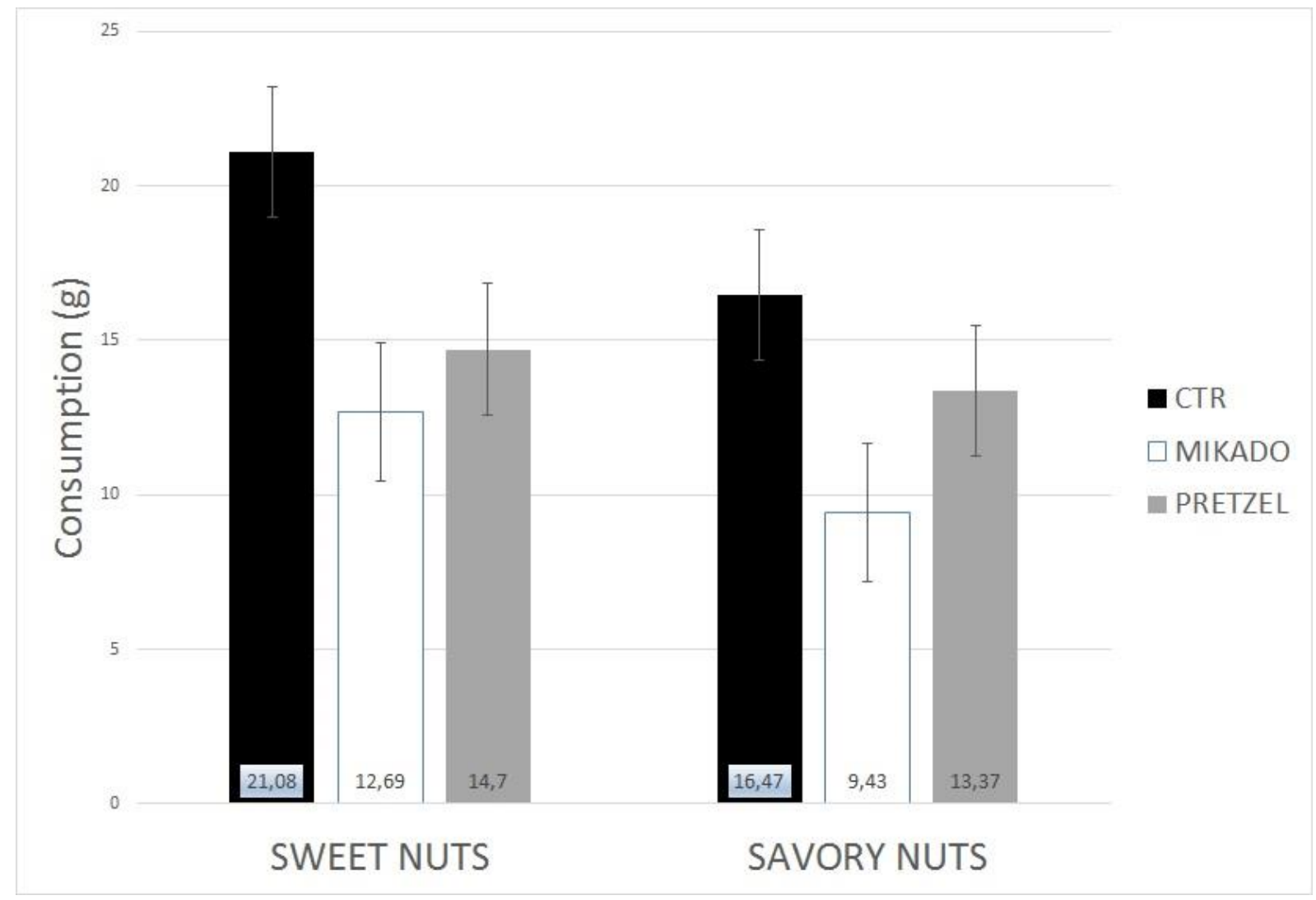

We also tested whether the sticks differed in their likeability. A repeated measure ANOVA (with the same dataset as the main analysis) on liking of the products of phase 1 showed a significant difference: $F(2,252)=124.95, p<.0001$. Chocolate sticks were liked better $(M=$ 61.82, $S E=2.44)$ than salty sticks $(M=47.16, S E=2.56)$, which were in their turn liked 
better than wooden sticks $(M=14.97, S E=1.86)$, with all pairwise contrasts significant at the $p<0.0001$ level.

Figure 3. The pre-exposure effect for sweet and savory snacks per gender. Performing a task with chocolate sticks (SWEET PE; white bars) or pretzel sticks (SALTY PE; grey bars) without eating these sticks induces reduced consumption of another tempting snack in a subsequent consumption phase in comparison with performing this task with wooden sticks (CTR; black bars). However, this effect was only significant in women. Bars represent estimated marginal means (collapsed across taste), displayed as the untransformed data to facilitate the interpretation, error bars represent the standard error of the mean.

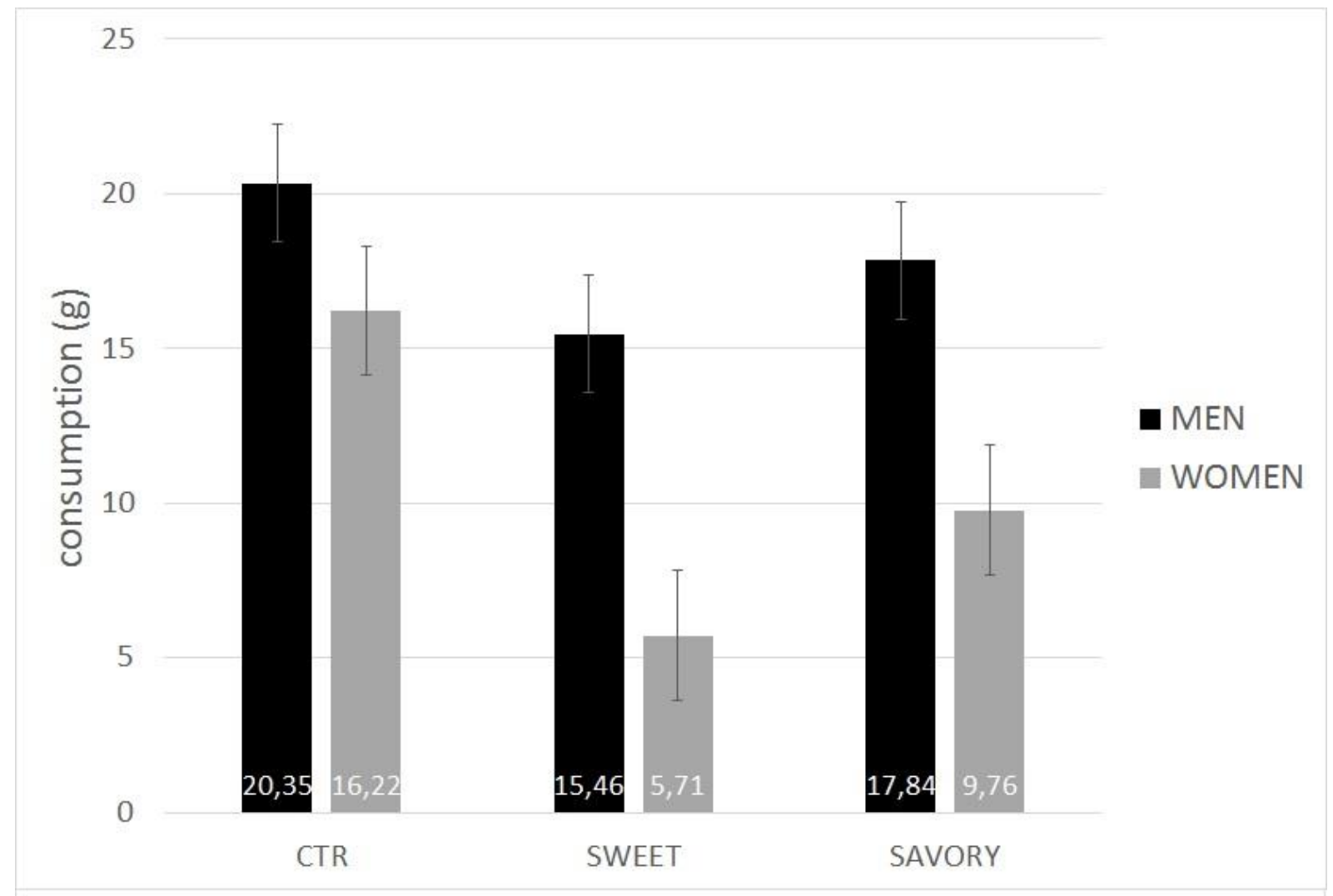

\section{Discussion}

Consumption of high-caloric food is generally too high. Prior research showed that preexposure to sweet snacks in a context of a task that conflicts with its consumption, reduces subsequent consumption of sweet snacks, at least in the lab. Despite its effectiveness for sweet temptations, the procedure had never been tested (to our knowledge) with savory temptations. Since overeating is not only caused by exposure to sweet temptations, we set out 
to test whether the pre-exposure effect can be produced with savory tempting foods, and second, whether the effect extends across tastes. The results revealed that the pre-exposure effect does not only hold for sweet snacks, but also for savory snacks, and actually crosses across tastes.

\subsection{Extending the pre-exposure effect}

The finding that the pre-exposure effect could be observed for sweet snacks, is important in two ways. First of all, it demonstrates that we could replicate the previously published effect (de Boer et al., 2015; Duh et al., 2016; Geyskens et al., 2008), with our adapted procedure. Since the original procedure published by Geyskens et al. (2008) did not allow for a condition with savory snacks similar to the Quality Street candies, we adapted both the first and the second phase. Via matchstick puzzles that had to be solved by using either chocolate/pretzel sticks or wooden sticks, we were able to induce exposure to a tempting stimulus in a situation that naturally prevented participants to consume the tempting food. To add a savory element in the second phase, we added a condition with a savory taste test (next to the sweet taste test). Our results indicate that we were able to induce a similar behavioral conflict as in the Geyskens et al. (2008) study, since we replicate the effect for sweet temptations. Second, this effect is demonstrated irrespective of the taste used in the taste test (sweet or savory), since there is no interaction with product taste.

Another important finding of this study is that the effect does not seem to be specific to exposure to sweet temptations, because we could produce the pre-exposure effect with exposure to salty snacks, again, irrespective of the taste used in the taste test. These results suggest that the pre-exposure effect is rather general than food specific, and that the behavioral conflict is more likely to be a conflict on the food temptation level, rather than on the level of the specific food product. Previous studies already demonstrated that the effect is not product specific, since these studies never used exactly the same product in phase 1 and 2 , mainly to conceal the link between the studies (e.g. Quality street candy and M\&M's; Duh et al., 2016; Geyskens et al., 2008). Our study broadens this and demonstrates that the effect even crosses tastes.

In addition, these results adds some valuable information to unravel the underlying processes. More specifically, because of this finding, habituation is less likely to be the crucial process explaining the pre-exposure effect. Habituation to food refers to the reduced responding to repeated food stimuli (Epstein et al., 2009). As such, the pre-exposure effect has been linked to habituation. However, one characteristic of habituation is that it is rather specific, 
especially when tested in a single study session (e.g. Epstein, Robinson, Roemmich, Marusewski, \& Roba, 2010). Hence, a reduction in the consumption of savory nuts (chocolate nuts) after exposure to chocolate sticks (salty sticks) cannot be explained by habituation. According to habituation theory, introducing a novel food (taste), induces an increase rather than a decrease in consumption (Epstein, Rodefer, Wisniewski, \& Caggiula, 1992). A possible mechanism is related to disgust. It is possible that handling the food in the first phase induces a mild feeling of disgust, which then affects the appetite in the second phase. Further research is called upon to disentangle what could be the process inducing the preexposure effect.

\subsection{The influence of gender on the pre-exposure effect}

The pre-exposure effect has been found for men and women in adult populations (Duh et al., 2016). As such, we decided to include both genders in our sample. In this study, we replicate the fact that men tend to eat more than women. However, unexpectedly, gender interacted with the pre-exposure manipulation, and the effects seem to be much stronger in women than in men.

This might indicate that women experienced the behavioral conflict differently in the preexposure phase than men. We see two plausible explanations for this unexpected interaction. First, women may find the tempting products used in the first phase more tempting. However, liking and attractiveness measures of the tempting products used in the pre-exposure phase (note: these were measured after the taste test) did not indicate differences between men and women in our study. Nevertheless, even with equal levels of attractiveness, women may still have been in conflict to a larger extent than men if the food was perceived as more forbidden to them than to men (Kroese, Evers, \& De Ridder, 2011). Future research should not only measure attractiveness but also degree of forbiddingness to test this hypothesis. Second, the degree of behavioral conflict may have been lower for men than for women because they were more involved in the specific task we used. If the involvement is very strong, the attention to the food may fade, and with it, the strength of the behavioral conflict. Future research could measure involvement or make sure that involvement is optimal in all groups. It may also be useful in future research to pre-test the tasks of phase 1 in the pre-exposure procedure for gender neutrality. Taken together, thus far, we have no strong evidence to explain why women would benefit more from the pre-exposure task than men. Further research is required to disentangle the role of gender in the pre-exposure effect. 


\subsection{Limitations and future research}

This study has several limitations. First of all, we assume that self-control processes transfer from phase 1 to phase 2, but the experimental procedure, as set up in this study (and as in most published studies; e.g. Duh et al., 2016) does not allow a general conclusion about the robustness of the procedure. The effect of pre-exposure on subsequent intake within minutes gives no information on how experiences or (cognitive) activities would affect the transfer from phase 1 to phase 2 . Thus far, one study showed that repeated applications of preexposure to tempting food lasted for at least 24-h in children aged between 8 and 11 years old (de Boer et al., 2015). To further explore the robustness and the longevity of the pre-exposure effect, more research is called upon in which the procedure is adapted with longer intervals and additionally, in which the type of interference is manipulated between the pre-exposure phase and the consumption phase. Second, the effect of the pre-exposure procedure was tested in the context of a taste test, both in this study and in prior studies. It remains to be confirmed that consumption in real life situations (e.g. snack or dessert consumption) would show a similar pattern. Third, and building on this, it would be interesting to see if the procedure would also work for vulnerable individuals, for instance overweight or obese individuals. Obese individuals have been shown to be particularly vulnerable to food temptations (Castellanos et al., 2015) so it remains to be seen if the procedure would work for them. Would obese individuals succeed in resisting the temptation in phase 1 , and would this resistance (if successful) transfer to the second phase? Fourth, measuring the temptation strength or state self-control during or right after the pre-exposure phase would give us more information on whether the sweet and savory snacks are inducing a similar level of conflict. For example, de Boer et al. (2015) used saliva measures as an implicit attractiveness measure for the tempting products. In the current study, measures on product attractiveness were only measured after the taste test (because of procedural considerations). Related to this point, more research is needed on the underlying processes of the pre-exposure effect. This effect holds promise to inspire strategies that allow consumers to better cope with the current tempting environment. With the view on applying this procedure to daily life, more information on what exactly is causing this effect is necessary.

\section{Conclusion}

This study shows the potential of the pre-exposure effect as a valuable procedure to reduce consumption of tempting food. Not only can this procedure reduce consumption of tempting 
sweet foods but it also extends to savory tasting food. This finding is especially important knowing that our daily environment is characterized by an abundance of tempting food products. These temptations that occur subsequently are seldom only sweet or food products of similar taste. We look forward o future research broadening the scope of this procedure to real-life consumption and consumption of vulnerables groups.

\section{Acknowledgements}

The contribution of the first author was supported by KU Leuven funding (C22/15/002).

\section{References}

Anschutz, D. J., Engels, R. C., van der Zwaluw, C. S., \& Van Strien, T. (2011). Sex differences in young adults' snack food intake after food commercial exposure. Appetite, 56(2), 255-260.

Appelhans, B. M., French, S. A., Pagoto, S. L., \& Sherwood, N. E. (2016). Managing temptation in obesity treatment: A neurobehavioral model of intervention strategies. Appetite, 96, 268-79. http://doi.org/10.1016/j.appet.2015.09.035

Baumeister, R. F. (2002). Yielding to Temptation: Self-Control Failure, Impulsive Purchasing, and Consumer Behavior. Journal of Consumer Research, 28(4), 670-676. http://doi.org/10.1086/338209

Benton, D. (2004). Role of parents in the determination of the food preferences of children and the development of obesity. International Journal of Obesity, 28(7), 858-869. http://doi.org/10.1038/sj.ijo.0802532

Birch, L. L. (2003). DEVELOPMENT OF FOOD PREFERENCES. http://dx.doi.org/10.1146/annurev.nutr.19.1.41.

Blundell, J. E., Stubbs, R. J., Golding, C., Croden, F., Alam, R., Whybrow, S., ... Lawton, C. L. (2005). Resistance and susceptibility to weight gain: Individual variability in response to a high-fat diet. Physiology \& Behavior, 86(5), 614-622. http://doi.org/10.1016/j.physbeh.2005.08.052

Castellanos, E. H., Charboneau, E., Dietrich, M. S., Park, S., Bradley, B. P., Mogg, K., \& Cowan, R. L. (2009). Obese adults have visual attention bias for food cue images: evidence for altered reward system function. International Journal of Obesity (2005), 33(9), 1063-73.

Chambaron, S., Chisin, Q., Chabanet, C., Issanchou, S., \& Brand, G. (2015). Impact of 
olfactory and auditory priming on the attraction to foods with high energy density. Appetite, 95, 74-80.

de Boer, C., de Ridder, D., de Vet, E., Grubliauskiene, A., \& Dewitte, S. (2015). Towards a Behavioral Vaccine: Exposure to Accessible Temptation when Self-Regulation is Endorsed Enhances Future Resistance to Similar Temptations in Children. Applied Psychology: Health and Well-Being, 7(1), 63-84. http://doi.org/10.1111/aphw.12037

Dewitte, S., Bruyneel, S., \& Geyskens, K. (2009). Self-Regulating Enhances Self-Regulation in Subsequent Consumer Decisions Involving Similar Response Conflicts. Journal of Consumer Research, 36(3), 394-405. http://doi.org/10.1086/598615

Duh, H. I., Grubliauskiene, A., \& Dewitte, S. (2016). Pre-exposure to food temptation reduces subsequent consumption: A test of the procedure with a South-African sample. Appetite. http://doi.org/10.1016/j.appet.2015.10.024

Epstein, L. H., Robinson, J. L., Roemmich, J. N., Marusewski, A. L., \& Roba, L. G. (2010). What constitutes food variety? Stimulus specificity of food. Appetite, 54(1), 23-29. http://doi.org/10.1016/j.appet.2009.09.001

Epstein, L. H., Rodefer, J. S., Wisniewski, L., \& Caggiula, A. R. (1992). Habituation and dishabituation of human salivary response. Physiology \& Behavior, 51(5), 945-950. http://doi.org/10.1016/0031-9384(92)90075-D

Epstein, L. H., Temple, J. L., Roemmich, J. N., \& Bouton, M. E. (2009). Habituation as a determinant of human food intake. Psychological Review, 116(2), 384-407.

Fedoroff, I., Polivy, J., \& Peter Herman, C. (2003). The specificity of restrained versus unrestrained eaters' responses to food cues: general desire to eat, or craving for the cued food? Appetite, 41(1), 7-13. http://doi.org/10.1016/S0195-6663(03)00026-6

Fishbach, A., Friedman, R. S., \& Kruglanski, A. W. (2003). Leading us not into temptation: Momentary allurements elicit overriding goal activation. Journal of Personality and Social Psychology, 84(2), 296-309. http://doi.org/10.1037/0022-3514.84.2.296

Gaillet-Torrent, M., Sulmont-Rossé, C., Issanchou, S., Chabanet, C., \& Chambaron, S. (2014). Impact of a non-attentively perceived odour on subsequent food choices. Appetite, 76, 17-22.

Geyskens, K., Dewitte, S., Pandelaere, M., \& Warlop, L. (2008). Tempt Me Just a Little Bit More: The Effect of Prior Food Temptation Actionability on Goal Activation and Consumption. Journal of Consumer Research, 35(4), 600-610. http://doi.org/10.1086/591106

Grubliauskiene, A., \& Dewitte, S. (2014). Temptation in the background: non-consummatory 
exposure to food temptation enhances self-regulation in boys but not in girls. Frontiers in Psychology, 5, 788. http://doi.org/10.3389/fpsyg.2014.00788

Herman, C. P., \& Polivy, J. (1975). Anxiety, restraint, and eating behavior. Journal of abnormal psychology, 84(6), 666.

Herman, C., \& Polivy, J. (1980). Restrained eating. In A. Stunkard (Ed.), Obesity (pp. 208 225). Philadelphia: Saunders.

Jansen, A., Houben, K., \& Roefs, A. (2015). A Cognitive Profile of Obesity and Its Translation into New Interventions. Frontiers in Psychology, 6, 1807. http://doi.org/10.3389/fpsyg.2015.01807

Kroese, F. M., Evers, C., \& De Ridder, D. T. D. (2009). How chocolate keeps you slim. The effect of food temptations on weight watching goal importance, intentions, and eating behavior. Appetite (Vol. 53).

Kroese, F. M., Evers, C., \& De Ridder, D. T. (2011). Tricky treats: Paradoxical effects of temptation strength on self-regulation processes. European Journal of Social Psychology, 41(3), 281-288.

Lambert, K. G., Neal, T., Noyes, J., Parker, C., \& Worrel, P. (1991). Food-related stimuli increase desire to eat in hungry and satiated human subjects. Current Psychology, 10(4), 297-303. http://doi.org/10.1007/BF02686902

Loth, K. A., MacLehose, R. F., Larson, N., Berge, J. M., \& Neumark-Sztainer, D. (2016). Food availability, modeling and restriction: How are these different aspects of the family eating environment related to adolescent dietary intake? Appetite, 96, 80-86. http://doi.org/10.1016/j.appet.2015.08.026

McSweeney F.K. \& Murphy, E.S. (2009). Habituation of reinforcement value even without consumption. Neurobiology of Learning and Memory 92, 189-198

Miller, E. K., \& Cohen, J. D. (2001). An integrative theory of prefrontal cortex function. Annual Reviews Neuroscience, 24, 167- 202.

Myrseth, K. O. R., Fishbach, A., \& Trope, Y. (2009). Counteractive self-control. Psychological Science, 20(2), 159-63. http://doi.org/10.1111/j.1467-9280.2009.02268.x

Papies, E. K., Stroebe, W., \& Aarts, H. (2008). The allure of forbidden food: On the role of attention in self-regulation. Journal of Experimental Social Psychology, 44(5), 12831292. http://doi.org/10.1016/j.jesp.2008.04.008

Ramaekers, M. G., Luning, P. A., Lakemond, C. M. M., van Boekel, M. A. J. S., Gort, G., Boesveldt, S., ... Wansink, B. (2016). Food Preference and Appetite after Switching between Sweet and Savoury Odours in Women. PLOS ONE, 11(1), e0146652. 
http://doi.org/10.1371/journal.pone.0146652

Schwartz, C., Issanchou, S., \& Nicklaus, S. (2009). Developmental changes in the acceptance of the five basic tastes in the first year of life. British Journal of Nutrition, 102(09), 1375-1385.

Scully, M., Dixon, H., \& Wakefield, M. (2009). Association between commercial television exposure and fast-food consumption among adults. Public Health Nutrition, 12(01), 105110.

Stein, L. J., Cowart, B. J., \& Beauchamp, G. K. (2012). The development of salty taste acceptance is related to dietary experience in human infants: a prospective study. The American journal of clinical nutrition, 95(1), 123-129.

Tangney, J. P., Baumeister, R. F., \& Boone, A. L. (2004). High Self-Control Predicts Good Adjustment, Less Pathology, Better Grades, and Interpersonal Success. Journal of Personality, 72(2), 271-324. http://doi.org/10.1111/j.0022-3506.2004.00263.x

Trope, Y., \& Fishbach, A. (2000). Counteractive self-control in overcoming temptation. Journal of Personality and Social Psychology, 79(4), 493-506. http://doi.org/10.1037//0022-3514.79.4.493

Walton, G. M., \& Cohen, G. L. (2003). Stereotype Lift. Journal of Experimental Social Psychology, 39(5), 456-467. http://doi.org/10.1016/S0022-1031(03)00019-2

Wansink, B., \& Sobal, J. (2007). Mindless Eating: The 200 Daily Food Decisions We Overlook. Environment and Behavior, 39(1), 106-123. http://doi.org/10.1177/0013916506295573

Whiteside, S. P., \& Lynam, D. R. (2001). The Five Factor Model and impulsivity: using a structural model of personality to understand impulsivity. Personality and Individual Differences, 30(4), 669-689. http://doi.org/10.1016/S0191-8869(00)00064-7 